\title{
THE INFLUENCE OF EPINEPHRINE ON THE DIGITAL ARTERIOLES OF MAN : A STUDY OF THE VASOCONSTRICTOR EFFECTS
}

\author{
By THOMAS J. FATHERREE ${ }^{1}$ AND EDGAR V. ALLEN
}

(From the Division of Medicine, The Mayo Clinic, Rochester, Minn.)

(Received for publication August 16, 1937)

The recent observations of Freeman, Smithwick and White $(1,7,8)$, who found increased sensitivity of the digital arterioles of human subjects to epinephrine following sympathetic ganglionectomy, have made it desirable to know more about the response of the circulation of normally innervated digits to the injection of epinephrine. According to these authors, who considered a decrease in temperature of the skin a manifestation of vasoconstriction, epinephrine in dilute solutions ( 1 part epinephrine hydrochloride to 250,000 parts of a physiological solution of sodium chloride ${ }^{2}$ ) when administered intravenously at a rate varying from 40 to 60 drops per minute produces relatively little vasoconstriction in the vessels in the skin of normally innervated digits. Inasmuch as some of our studies gave results contrary to this, a more thorough investigation was thought advisable, and during the course of our investigations other observations were made relative to vasoconstriction in the digits following injections of epinephrine.

\section{METHODS OF STUDY}

The technic used in our studies was essentially that described by Freeman and associates. Subjects lay on a couch, with a light blanket over the trunk and with their hands and feet exposed to a room temperature between $24^{\circ}$ and $27^{\circ} \mathrm{C}$., for a sufficient period to allow the temperature of the skin of the digits to become fairly stable (usually from thirty minutes to an hour). In some instances the initial temperature of the digits was too low to allow satisfactory demonstration of the vasoconstrictor action of epinephrine, and it was found necessary to elevate the temperature of the skin by means of a heat cabinet which warmed

1 Fellow in Medicine, The Mayo Foundation.

2 Throughout this paper when " epinephrine" or " solution of epinephrine" is referred to, it indicates that this preparation was injected intravenously. the air about the trunk to from 40 to $60^{\circ} \mathrm{C}$., the hands and feet then being exposed to room temperature. $^{3}$ In such cases the heat cabinet was allowed to remain in place throughout the experiment. This procedure was necessary because of the obvious fact that one cannot demonstrate the vasoconstrictor action of a drug when the vessels are primarily in a state of marked vasoconstriction. In our studies, when the temperature of the digits had reached a fairly stable level, the intravenous infusion of physiological saline solution was begun, using the gravity method. Then, without the patient's knowledge, injection of the epinephrine solution was begun and was continued for varying periods of time. The change in injection from physiological saline solution to a solution of epinephrine was accomplished by means of a Y-tube, the lower end of which was connected with a needle inserted into the lumen of a vein. The buret containing the physiological saline solution was attached to one of the upper arms of the tube, and the buret containing the epinephrine solution to the other. The rate of injection of epinephrine was sufficiently rapid to produce a minimal elevation of systolic blood pressure of $20 \mathrm{~mm}$. $\mathrm{Hg}$. When the period of epinephrine injection was over, physiological saline solution was usually allowed to run into the vein for a short period thereafter.

The procedure just described was followed in order to eliminate as much as possible the psychic factors that might influence the skin temperatures had the patient known the moment the injection of epinephrine was begun and stopped. During

3 It should be noted here that in the figures in which the experimental results are recorded the room temperature is indicated by a straight line. This procedure was used to meet the expediency of clear illustration, and is not to be taken as indicating a constant environmental temperature. In reality the room temperature varied over a range corresponding approximately to the temperature indicated plus or minus $1^{\circ} \mathrm{C}$. 
the entire experiment the blood pressure and pulse rate were noted at short intervals, and the temperatures of the skin of the volar surfaces of the distal phalanges of several of the digits of the upper and lower extremities were determined at three to five-minute intervals by an electromotive thermometer of the type described by Sheard (6).

The importance of having sufficient initial vasodilatation. Lewis has pointed out that a certain amount of vasoconstriction is a necessary prerequisite for the demonstration of vasodilatation. In a like manner, as has been indicated, the presence of some initial vasodilatation is necessary for the demonstration of vasoconstriction. If, for example, the temperature of the environmental air is $30^{\circ} \mathrm{C}$. and that of the skin of the digits is $30^{\circ} \mathrm{C}$., vasoconstriction cannot be demonstrated since no amount of it will cause the temperature of the skin to be decreased much below that of the room. Stated in another manner, the temperature of the skin must exceed that of the room by several degrees Centigrade if significant vasoconstriction is to be demonstrated. Furthermore, for comparative purposes in different experiments, the digital temperature must exceed that of the environmental air by approximately the same degree. An illustration of this is as follows. If the temperature of the air in the room is $28^{\circ} \mathrm{C}$. and that of the digits is $30^{\circ} \mathrm{C}$., the intravenous injection of epinephrine could cause a decrease in digital temperature only of about $2^{\circ} \mathrm{C}$. If, however, after ganglionectomy the digital temperature was $32^{\circ} \mathrm{C}$., the injection of epinephrine could cause a decrease in it of about $4^{\circ} \mathrm{C}$. The conclusion that such an experiment indicated increased sensitivity on the occasion of the second study would not be justified.

These points, probably because of their very obviousness, have not been particularly emphasized in the literature. The necessity for having sufficient vasodilatation before the vasoconstrictor stimulus is applied, if vasoconstriction is to be demonstrated, is clearly shown in Figure 1. The failure of the epinephrine to produce vasoconstriction when the temperature of the skin was low was a result of the fact that the vessels were already in a state of vasoconstriction of sufficient degree to lower the temperature of the digits to approximately that of the room. The availability of vasodilatation is shown by the increase in tem-

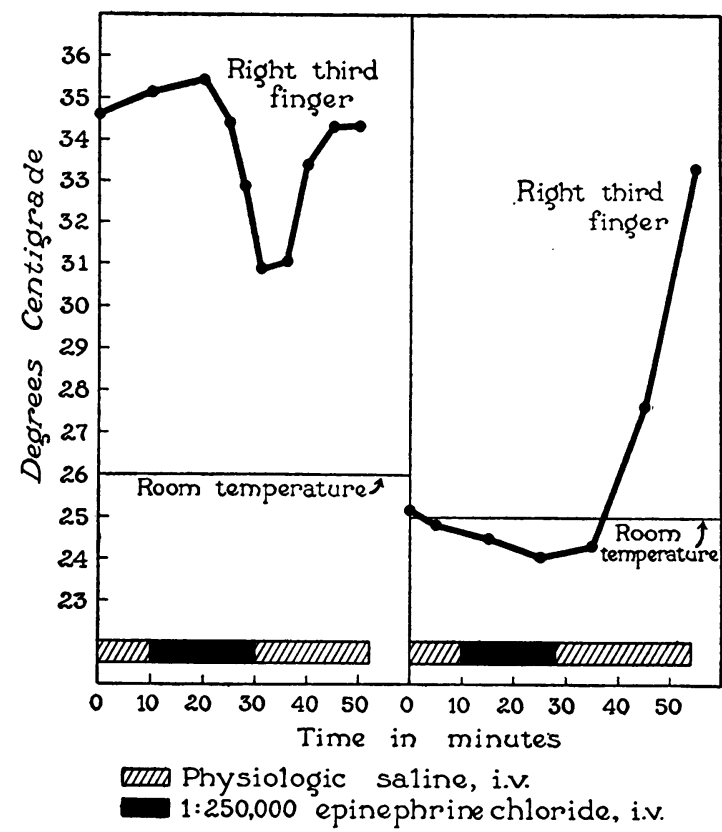

Fig. 1. Studies on a Normally Innervated EXTREMITY

Two injections of epinephrine were made into a vein of the same hypertensive patient approximately a month apart, the patient having undergone anterior rhizotomy of the lower thoracic and upper lumbar regions in the interval. There was no disturbance of innervation of the upper extremities, but the temperature of the skin of the fingers was decreased following operation. When the temperature of the skin was relatively great, the intravenous injection of a $1: 250,000$ solution of epinephrine at a rate of $3.9 \mathrm{cc}$. per minute caused a decrease of the skin temperature; the same procedure carried out at a rate of $5.3 \mathrm{cc}$. per minute had very little effect when the temperature of the skin of the same finger was low before the injection was made.

perature of the skin after the intravenous injection was discontinued.

In order to have some practical criterion to evaluate our findings to greater advantage, we decided on $30^{\circ} \mathrm{C}$. as the requisite minimal skin temperature at the beginning of the injections of epinephrine. In an environmental temperature not exceeding $27^{\circ} \mathrm{C}$., a good degree of vasoconstriction can be demonstrated. Hence, in all experiments recorded here, unless otherwise noted, it may be assumed that the temperature of the skin at the time the injection of epinephrine was started was $30^{\circ} \mathrm{C}$. or greater.

The effect of vasodilatation on the peripheral vasoconstrictor action of epinephrine induced by 
heating the trunk. In order to elevate the skin temperature of the digits of some individuals to a level sufficiently high to allow adequate demonstration of the vasoconstrictor effect of the epinephrine, we adopted the method described by Lewis and Pickering (4), namely, of heating the trunk and leaving the hands and feet exposed. Such a procedure ordinarily produces peripheral vasodilatation in the extremities. Vasodilatation induced reflexly by heat might, however, be opposed to the vasoconstrictor effect of epinephrine which we were attempting to demonstrate, and it might interfere with the vasoconstricting effect of the epinephrine. That it did not is demonstrated in Figure 2. Because of this observation, which was made repeatedly, we elevated the digital skin temperature by means of heat applied to the trunk and abdomen in certain of our studies without fear of interfering with the results. Incidentally, however, we have observed that vasodilatation in the feet of certain individuals cannot be produced by an environmental temperature of 40 to $60^{\circ} \mathrm{C}$. about the trunk. It might therefore be assumed

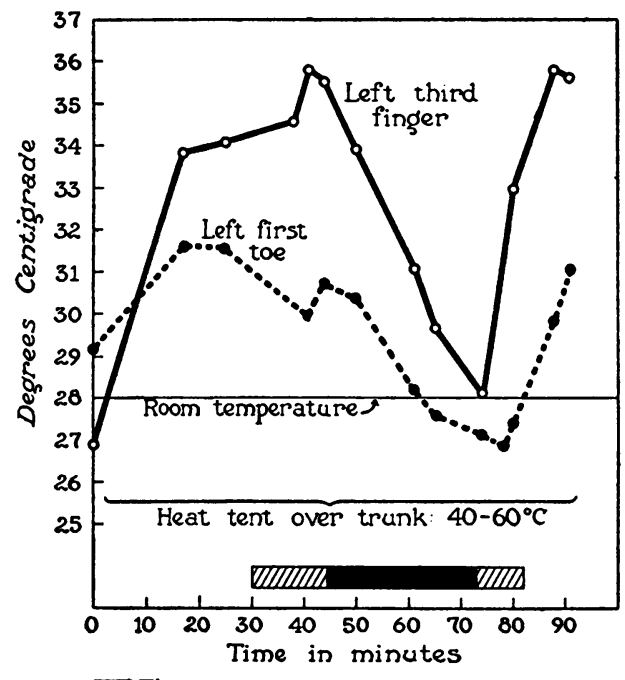

III Physiologic saline, i.v.

1:250,000 epinephrine chloride, i.v.

Fig. 2. Studies on Normally InNervated Extremities, 'Showing that the Peripheral Vasodilatation Produced by Warming the Trunk has No Appreciable InHibiting Effect on the Digital Vasoconstrictive Action of Epinephrine Chloride Which, when InJected Intravenausly, Caused the Temperature of the Skin of Both Finger and Toe to Decrease to THAT OF THE ROOM

The rate of injection was $6.5 \mathrm{cc}$. of epinephrine solution per minute.

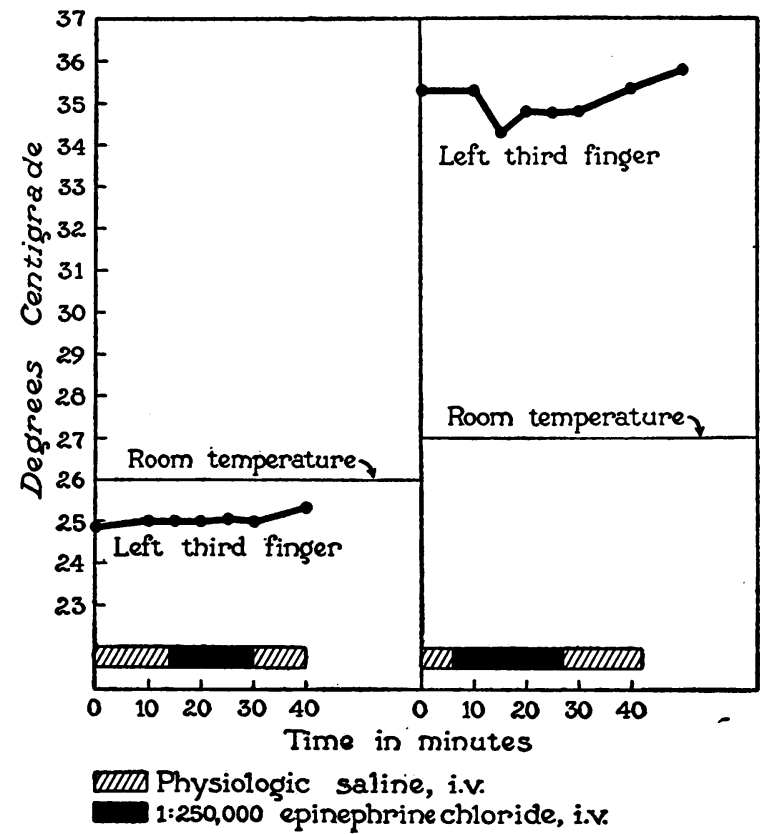

Fig. 3. Studies on a Normally InNERvated Extremity

Two injections of epinephrine were given the same patient with the skin temperature at different levels. The failure of epinephrine to produce vasoconstriction in the instance recorded on the right when the skin temperature was $35^{\circ} \mathrm{C}$. shows that the presence of vasodilatation does not insure vasoconstriction when epinephrine is injected at a rate of $11.4 \mathrm{cc}$. per minute.

from the preceding that if the skin temperature exceeds that of the environmental air by several degrees Centigrade, vasoconstriction can be demonstrated regularly following injections of epinephrine. Figure 3 shows the fallacy of such an assumption, for in some instances the injection of epinephrine failed to provoke vasoconstriction even when there was acceptable vasodilatation before the injection was begun.

The variability of the vasoconstrictor response in the digits of the same individual. It appeared to us important to know whether or not the vasoconstrictor response in the digits of the same individual to the intravenous injection of epinephrine, given in the same manner and amounts, is constant or variable in degree. Consequently, studies were performed on one individual who was without clinical vasomotor disturbances using four successive changes in the temperature of the skin of the same toe and that of the same finger as evidence of vasoconstriction in all four studies and injecting the solution of epinephrine intravenously 
at approximately the same rate, and hence injecting nearly identical amounts of epinephrine in each of the four studies. The results are widely variable (Figures 4 and 5 ). In some instances, arterioles of the digits of the upper and lower extremities might react differently to epinephrine. Five individuals with normally innervated extremities were accordingly studied. It is ap-

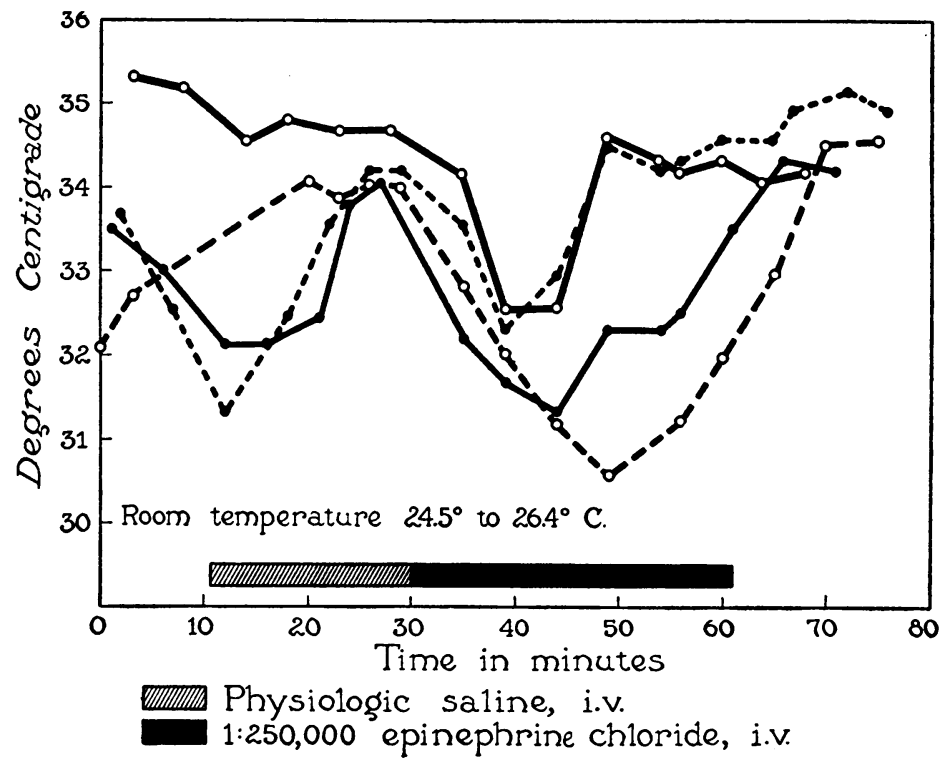

Fig. 4. Studies on a Normally InNervated Extremity

The effect of intravenous injections of epinephrine chloride on the temperature of the skin of the left third finger of an individual without vascular disease on four different occasions. On all occasions the epinephrine was administered under as nearly similar conditions as possible, the time of injection being constant and the rate of injection being practically constant ( 4.8 to $5.0 \mathrm{cc}$. per minute). There was a wide variability in the changes in the temperature of the skin which resulted from the injection.

the decreases in skin temperature were great, in others they were small. Similar variability was shown in three successive studies of sensitivity of the digital arterioles of a patient with Raynaud's disease. We can draw no conclusion from our studies but that the response of the skin temperature of the digits to the intravenous injection of a solution of epinephrine cannot be used as an indication of the condition of sympathetic innervation. All the results of our subsequent studies as well as of those published previously must be considered with full recognition that this is true.

The relative effect of epinephrine on the temperature of the skin of the fingers and toes. Inasmuch as there is a greater resistance to vasodilatation in the lower extremities than in the upper extremities $(2,5)$, it appeared possible that the parent from our studies that the individual digits of the same subject vary widely in their response to the injection of epinephrine. There is no constant difference in the magnitude of the vasoconstrictor response of the vessels of the fingers as contrasted with that of the toes. Since skin temperatures of the fingers are ordinarily considerably higher than those of the toes when epinephrine is injected, the magnitude of the decrease of the skin temperature of the fingers may be greater than that of the toes. In order to standardize the conditions of the study we therefore arranged the environmental temperature so that the skin temperatures of the fingers and the toes were at about the same level when epinephrine was injected. The results of a study of seven individuals are presented in Table I. It would 


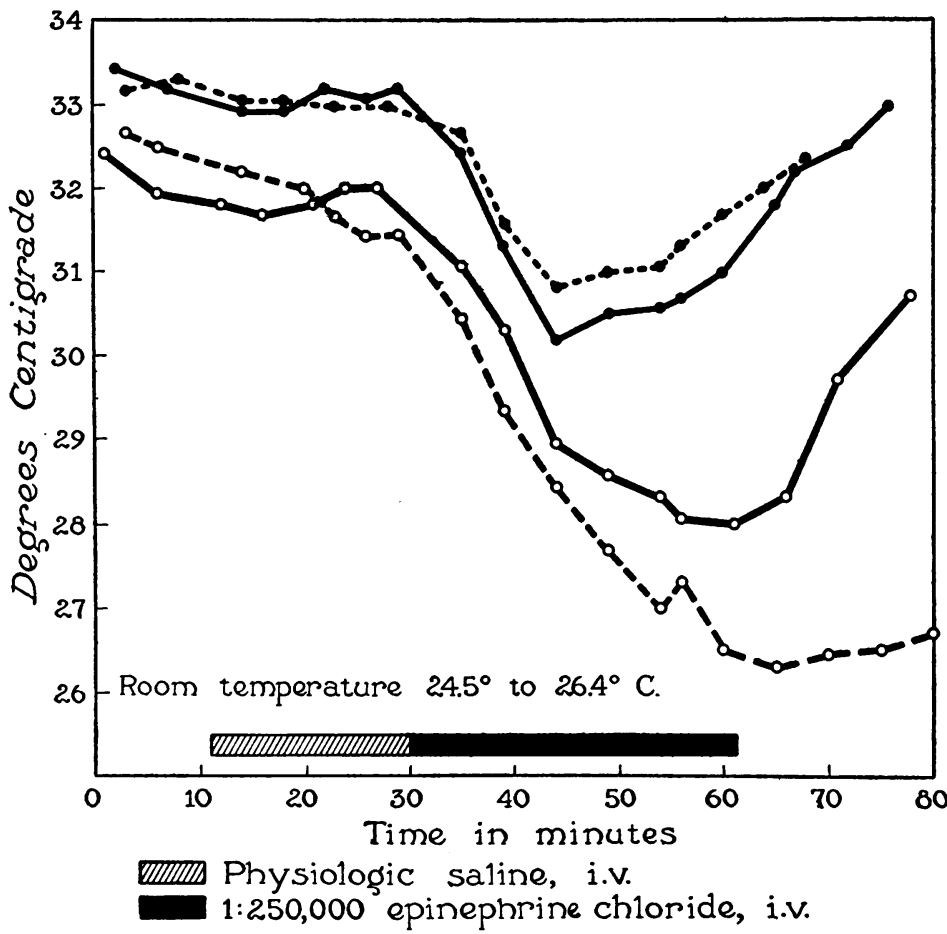

Fig. 5. Studies on a Normaliy Innervated Extremity

The effect of intravenous injections of epinephrine chloride on the temperature of the skin of the right third toe of the same individual as in Figure 4 on four different occasions. These measurements of skin temperature were made simultaneously with those in Figure 4, and hence the conditions of the experiments were the same. Here an even wider range of variation in the skin temperature of the toe occurred as a result of the injections of epinephrine.

TABLE I

Studies on normally innervated extremities, showing relative vasoconstrictor effect of epinephrine in the fingers and toes*

\begin{tabular}{r|c|c|c|c}
\hline \hline Sub- & $\begin{array}{c}\text { Average } \\
\text { temperature } \\
\text { of fingers } \\
\text { before } \\
\text { injection of } \\
\text { epinephrine }\end{array}$ & $\begin{array}{c}\text { Average de- } \\
\text { crease in skin } \\
\text { temperature } \\
\text { of fingers as } \\
\text { result of } \\
\text { injection }\end{array}$ & $\begin{array}{c}\text { Average } \\
\text { temperature } \\
\text { of toes } \\
\text { before } \\
\text { injection of } \\
\text { epinephrine }\end{array}$ & $\begin{array}{c}\text { Average } \\
\text { decrease in } \\
\text { temperature } \\
\text { of the toes } \\
\text { as a result } \\
\text { of injections }\end{array}$ \\
\hline & $\circ C$. & $\circ C$. & $\circ C$. & $\circ C$. \\
19 & 32.3 & 3.4 & 32.6 & 0.8 \\
2 & 36.0 & 1.9 & 35.7 & 3.0 \\
21 & 33.9 & 3.6 & 33.7 & 3.5 \\
22 & 35.8 & 2.0 & 35.8 & 4.0 \\
23 & 34.9 & 3.3 & 35.9 & 4.3 \\
15 & 33.5 & 2.2 & 33.3 & 1.6 \\
\hline
\end{tabular}

* Immediately before epinephrine was injected the skin temperatures of the fingers and toes of a single subject were approximately the same, that is, the temperature of all the fingers measured were $1^{\circ} \mathrm{C}$. of that of all the toes measured. It may be seen that there was no constantly greater decrease in the skin temperature of either the toes or the fingers of the seven individuals measured. Subjects 22 and 15 were normals; Subjects 19 and 20 had sclerodactylia with associated Raynaud's phenomena; Subject 2 appear that under these circumstances there is no constant difference between the vasoconstrictor effect of epinephrine on the fingers and toes of these individuals. Opposite results were noted in the case of the two normal subjects, and the results were at variance in the study of the two subjects with sclerodactylia. In Figure $6 a$, however, it will be seen that the vasoconstrictor effect is less rapid and more persistent, and the return of the temperature of the skin toward the pre-injection level is less rapid in the toe than in the finger. In Figure $6 b^{4}$ the decrease in the temperature of the

4 The data represented in this and other charts of a similar type in this paper were obtained in the following manner. The value representing the maximal vasoconstrictor effect in a given individual, in the fingers for instance, was the greatest decrease in skin temperature

had a paraganglioma with paroxysmal hypertension; Subject 21 had essential hypertension, and Subject 23 had postural hypotension. 
skin of the fingers and toes produced by the intravenous injection of epinephrine chloride into five individuals is presented. In general, those individuals showing a marked decrease of the temperature of the skin of the fingers will also show a similar decrease in the toes. The extent strate results in the response of the temperature of different digits which, if presented without knowledge of the above observations, might well indicate increased sensitivity resulting from sympathectomy reported in previous publications (1, 7).

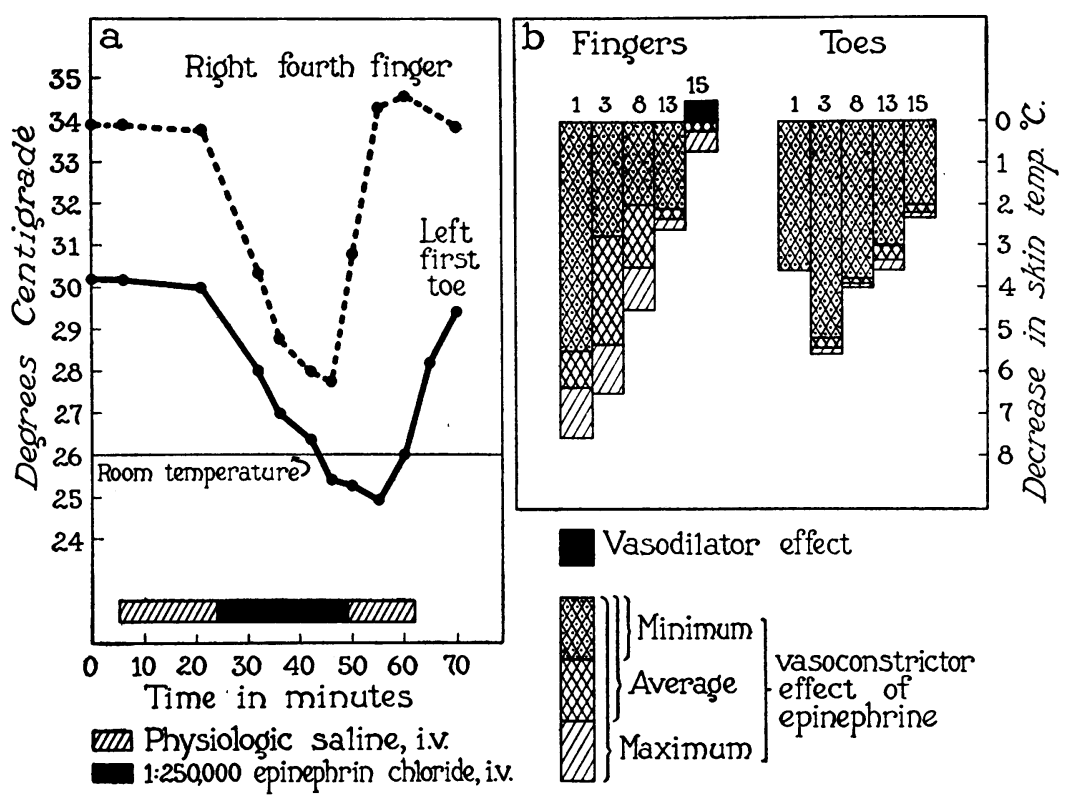

Fig. 6. Studies on Normally Innervated Extremities, Showing the Relative Effect of Intravenous Injections of Epinephrine Chloride on the Temperature of the Skin of the Fingers and Toes

of the decrease in the temperature of the skin is less variable in the individual toes than in the fingers of a single subject. The corresponding numbers above the columns in $b$ represent the same subject. Surprisingly, the response of the temperature of different digits of the same individual varies widely following the intravenous injection of epinephrine. However, this variability in response is less in the toes than in the fingers (Figure 6b).

In our study of individuals who have not undergone sympathetic denervation we can demon-

\footnotetext{
(expressed in degrees C.) which occurred as a result of injection of epinephrine, in a single finger among the several fingers measured. The minimal vasoconstrictor effect in a given individual was the smallest decrease in skin temperature which occurred in a single finger among the several fingers 'measured, and the average vasoconstrictor effect in a given individual was the average decrease in temperature as a result of the injection of epinephrine in all the fingers measured.
}

The variability of the vasoconstrictor effect in the normally innervated extremities of different subjects. It has been emphasized by White (8), and by Smithwick and his associates (7), that following prolonged injection of epinephrine, the normally innervated extremity shows comparatively little change in surface temperature and color. This observation is of considerable importance with regard to the evaluation of the sensitivity of the digital vessels to injections of epinephrine following sympathectomy, particularly in view of the suggestion by these authors that this procedure might be used to determine the completeness of sympathectomy. The results of our study of eighteen individuals with normally innervated extremities are presented in Figure 7 and Table II which show that neither the rate nor the time of injection is the determining factor. For example, contrast results in Subjects 4 and 15 for vasoconstrictor effects in the fingers and contrast results 
TABLE II

Studies on normally innervated extremities. Rates and times of injection

\begin{tabular}{|c|c|c|}
\hline Subject & Rate of injection & Injection time \\
\hline $\begin{array}{r}1 \ldots \\
2 \ldots \\
3 \ldots \\
4 \ldots \\
5 \ldots \\
6 \ldots \\
7 \ldots \\
8 \ldots \\
90 \\
11 \ldots \\
12 \ldots \\
13 \ldots \\
14 \ldots \\
15 \ldots \\
16 \ldots \\
17 . \\
18 \ldots\end{array}$ & 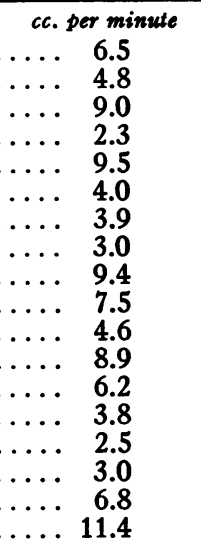 & $\begin{array}{c}\text { minutes } \\
26 \\
25 \\
25 \\
21 \\
22 \\
24 \\
18 \\
33 \\
25 \\
18 \\
15 \\
18 \\
17 \\
30 \\
28 \\
28 \\
20 \\
21\end{array}$ \\
\hline
\end{tabular}

response of the temperature of the skin in some of these studies is as great or greater than some of those presented by Freeman, Smithwick and White (1) to demonstrate increased sensitivity to epinephrine following postganglionic sympathectomy. Ordinarily, color changes in the digits were not conspicuous in these normally innervated extremities as a result of the injection of epinephrine. Cyanosis was observed in the fingers of Subject 2, but it disappeared rapidly with the discontinuance of the injection of epinephrine. There appears to be no correlation between the degree of sensitivity of the digital vessels to epinephrine and the occurrence of clinical vasospastic symptoms. Our subjects who showed the most marked vasoconstriction in the fingers as a result of epinephrine (Subjects 1,2,3,4, and 5) gave

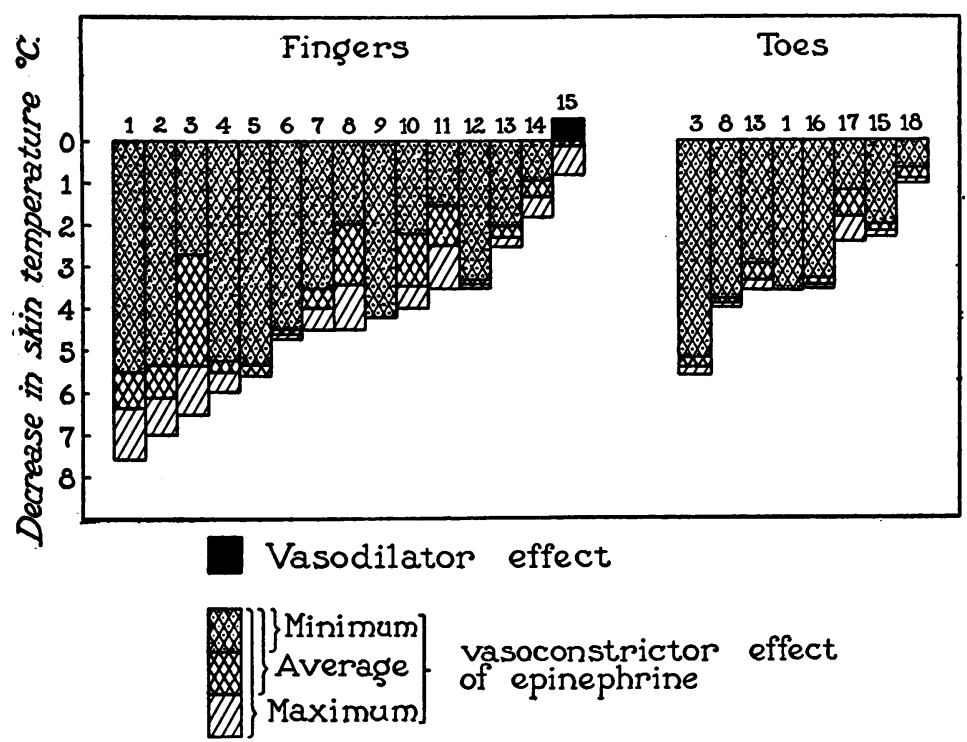

Fig. 7. Studies on Normaliy Innervated Extremities, Showing That the Effect of the Intravenous InJection of Epinephrine on the Skin Temperature of the Digits of Eighteen Subjects Varies from a Marked Decrease to a Suight Increase, thus Indicating a Wide VARIABIIITY IN THE VAsoconstrictor EFfect of EPINEPHRINE

Subjects 1, 4, 6, 11, 15 and 16 had no vascular disease; Subjects 3, 9 and 12 showed an abnormally high blood pressure response to the cold pressor test described by Hines and Brown (9); Subjects 2, 5, 7, 8, 10, 13,14 and 17 had essential hypertension, and Subjects 12 and 18 had mild symptoms of a vasospastic nature in the hands and feet.

in Subjects 13 and 18 for vasoconstrictor effects in the toes. The vasoconstriction obtained by injecting epinephrine in dilute solution varies over a very wide range in different individuals. The no history of pallor or cyanosis of the fingers as a result of exposure to cold or of emotional upsets, whereas in the case of the two subjects who did have symptoms of a vasospastic nature as a 
result of exposure to cold (Subjects 12 and 18), the response to epinephrine was relatively slight. The results of our studies are, therefore, in complete disagreement with those of Smithwick, Freeman and White, who stated that "The normally innervated extremity shows comparatively little change in surface temperature or color."

\section{COMMENT}

Our studies therefore indicate that the magnitude of the vasoconstrictor effect of the intravenous injection of epinephrine, demonstrated by determinations of the skin temperature, depends in part on the degree of vasodilatation present before the injection was begun. It is apparent, also, that in order to compare the results of injecting epinephrine into the blood on different occasions, as for example before and after sympathectomy, it is important to have the circumstances of the two investigations as nearly as possible the same. More particularly, the room temperature and the digital temperature at the beginning of the injection must be approximately identical. This can ordinarily be accomplished by using a baker over the trunk to produce vasodilatation reflexly. However, even when suitable vasodilatation is present, an appreciable degree of vasoconstriction may not be demonstrated following the injection of epinephrine. Moreover, the temperature of the skin of a digit of one individual may vary greatly on different 'occasions even when all the circumstances of the studies, such as the skin temperature, room temperature, and rate of injection of the epinephrine, are as nearly as possible the same.

The temperatures of different digits of the same individual respond in a widely variable degree to the intravenous injection of epinephrine; the same wide variability may be noted in the temperature of the digits of different individuals with apparently normally innervated extremities. In other words, there may be a remarkable variation in the response of the temperatures of the skin of the same digit of the same individual on different occasions, and of the digits of different individuals and of different digits of the same individual, to the injection of epinephrine into the blood stream, in the case of subjects all of whom have " normally innervated extremities." We have no explanation for this situation. The variability of response of the digits of different individuals might be based on a difference in "sympathetic tonus" in different individuals, but it seems illogical to assume that such a difference exists in different digits of the same individual. The pattern of response of the temperatures of the skin of the toes compared with those of the fingers is also widely variable. There is no consistent predominance of the vasoconstrictor response in either the toes or fingers as a result of the injection of epinephrine.

Freeman, Smithwick and White have concluded that, following cervicothoracic ganglionectomy, the digital vessels constrict more as a result of the injection of epinephrine than they do before this procedure. They have advanced the hypothesis (7) that this increase in sensitivity of the digital vessels to epinephrine accounts for some of the recurrence of symptoms in Raynaud's disease following the operation. In support of this hypothesis, however, they have offered no evidence from a study of patients other than that the digital vessels denervated by postganglionic section show a rather marked vasoconstrictor response to epinephrine whereas normally innervated digital vessels manifest a much lessened vasoconstrictor response to it. In contrast, our studies with a larger number of patients demonstrate conclusively that some individuals with normally innervated extremities may show a relatively great decrease in the skin temperature of the digits as a result of the injection of epinephrine. In fact, vasoconstriction induced by epinephrine was greater in some of our normal subjects than that demonstrated in some instances by Freeman, Smithwick and White following ganglionectomy. Furthermore, none of our subjects who so responded gave a history of vasospastic symptoms as a result of exposure to cold or emotional upset, although the two patients who did have such symptoms showed a relatively slight vasoconstrictor response to epinephrine. It appears, therefore, that marked vasoconstriction resulting from the intravenous injection of epinephrine does not indicate that vasomotor symptoms affect the digits. It appears also that vasomotor symptoms affecting the digits do not necessarily indicate great sensitivity of digital arterioles to epinephrine, and that great sensitivity of digital 
arterioles to injection of epinephrine does not indicate that postganglionic section of sympathetic nerves has been performed. As a result of our studies we cannot agree with the observations of Smithwick, Freeman and White that ". . . this test enables us to prove whether or not an extremity is completely sympathectomized." The observations of Freeman, Smithwick and White show that some of their patients who underwent ganglionectomy for Raynaud's disease had a relatively great decrease in the temperature of the skin of the digits following the injection of epinephrine, yet the patients did not have the color changes indicating Raynaud's disease. The conclusion from these observations is that a marked decrease in the skin temperature of the digits as a result of the injection of epinephrine does not indicate that vasospastic symptoms occur in these digits as a result of sensitivity to epinephrine.

It would appear, therefore, that the evidence is not conclusive that the heightened vasoconstrictor effect of epinephrine on the digital arterioles following ganglionectomy is the cause of recurrent symptoms in individuals with Raynaud's disease. While neither the possibility nor the plausibility of this explanation can be denied from our present studies, we wish to point out that it is not an established fact. Subsequent studies on the effect of injections of epinephrine before and after various operations on the sympathetic nervous system will be reported.

\section{SUMMARY AND CONCLUSIONS}

The demonstration of the vasoconstrictor effect of epinephrine on the digital arterioles requires sufficient vasodilatation which may be obtained satisfactorily in the upper extremities (and at times in the lower extremities also) by placing a heat tent over the trunk. This procedure does not impair the vasoconstrictor effect of epinephrine. However, even under these circumstances the injection of epinephrine into the veins of patients with normally innervated extremities may not cause significant vasoconstriction.

For comparative purposes, the temperatures of the skin of the digits of an individual and the temperature of the environmental air must be approximately the same on the different occasions of a study of the effect of injecting epinephrine. Even under these circumstances the results are very variable.

In normally innervated extremities, epinephrine ordinarily produces a slower but more prolonged vasoconstrictor effect in the toes than in the fingers, but there is no constant difference in the magnitude of vasoconstriction in the fingers as contrasted with that in the toes induced by the injection of epinephrine.

In subjects with normally innervated extremities, the vasoconstrictor effect of epinephrine on digital arterioles varies widely. Marked variability in the response of the skin temperature of different digits of the same individual and in the response of the skin temperature of the same digit of the same individual on different occasions has been noted. We doubt that the response of the temperature of the skin of the digits to the intravenous injection of epinephrine is as reliable a test as has been previously reported.

Patients with vasomotor symptoms suggesting Raynaud's disease do not necessarily possess arterioles which are unduly sensitive to epinephrine. Conversely, great sensitivity of digital arterioles to epinephrine does not necessarily indicate that vasomotor symptoms occur clinically. These observations cast some doubt on the conclusion that the recurrence of vasomotor symptoms after ganglionectomy for Raynaud's disease is due to an increased sensitivity of the arterioles to epinephrine.

\section{BIBLIOGRAPHY}

1. Freeman, N. E., Smithwick, R. H., and White, J. C., Adrenal secretion in man; the reactions of the blood vessels of the human extremity, sensitized by sympathectomy to adrenalin and to adrenal secretion resulting from insulin hypoglycemia. Am. J. Physiol., 1934, 107, 529.

2. Horton, B. T., Roth, Grace M., and Adson, A. W., Observations on some differences in the vasomotor reactions of the hands and feet. Proc. Staff Meet., Mayo Clin., 1936, 11, 433.

3. Lewis, Thomas, Observations upon the reactions of the vessels of the human skin to cold. Heart, 1930, $15,177$.

4. Lewis, Thomas and Pickering, G. W., Vasodilatation in the limbs in response to warming the body; with evidence for sympathetic vasodilatator nerves in man. Heart, 1931, 16, 33. 
5. Pickering, G. W., and Hess, W., Vasodilatation in the hands and feet in response to warming the body. Clin. Sc., 1933, 1, 213.

6. Sheard, Charles, The electromotive thermometer: an instrument and a method for measuring intramural, intravenous, superficial and cavity temperatures. Am. J. Clin. Path., 1931, 1, 209.

7. Smithwick, R. H., Freeman, N. E., and White, J. C., Effect of epinephrine on the sympathectomized human extremity: an additional cause of failure of operations for Raynaud's disease. Arch. Surg., 1934, 29, 759.

8. White, J. C., The Autonomic Nervous System; Anatomy, Physiology and Surgical Treatment. Macmillan Co., New York, 1935.

9. Hines E. A., and Brown, G. E., A standard test for measuring the variability of blood pressure: its significance as an index of the pre-hypertensive state. Ann. Int. Med., 1933, 7, 209. 